Review Article

\title{
Pathogenetic mechanisms in usual interstitial pneumonia/idiopathic pulmonary fibrosis
}

\author{
Eric S White,* Michael H Lazar and Victor J Thannickal \\ Division of Pulmonary and Critical Care Medicine, Department of Internal Medicine, University of Michigan Medical School, Ann Arbor, MI, USA
}

* Correspondence to: Eric S White, MD, University of Michigan Medical Center, Department of Internal Medicine, Division of Pulmonary and Critical Care Medicine, 630I MSRB III, I 150 W Medical Center Drive, Ann Arbor, Ml 481 09-0642. USA.

E-mail: docew@umich.edu
Received: 4 March 2003

Revised: 3 April 2003

Accepted: 21 May 2003

\begin{abstract}
Idiopathic pulmonary fibrosis (IPF) is a progressive, usually fatal, form of interstitial lung disease characterized by failure of alveolar re-epithelialization, persistence of fibroblasts/myofibroblasts, deposition of extracellular matrix, and distortion of lung architecture which ultimately results in respiratory failure. Clinical IPF is associated with a histopathological pattern of usual interstitial pneumonia (UIP) on surgical lung biopsy. Therapy for this disease with glucocorticoids and other immunomodulatory agents is largely ineffective and recent trials of newer anti-fibrotic agents have been disappointing. While the inciting event(s) leading to the initiation of scar formation in UIP remain unknown, recent advances in our understanding of the mechanisms underlying both normal and aberrant wound healing have shed some light on pathogenetic mechanisms that may play significant roles in this disease. Unlike other fibrotic diseases of the lung, such as those associated with collagen vascular disease, occupational exposure, or chemotherapeutic agents, UIP is not associated with a significant inflammatory response; rather, dysregulated epithelial-mesenchymal interactions predominate. Identification of pathways crucial to fibrogenesis might offer potentially novel therapeutic targets to slow or halt the progression of IPF. This review focuses on evolving concepts of cellular and molecular mechanisms in the pathogenesis of UIP/IPF. Copyright (c) 2003 John Wiley \& Sons, Ltd.
\end{abstract}

Keywords: pulmonary fibrosis; myofibroblast; extracellular matrix; alveolar epithelial cell; fibrogenesis

\section{Introduction}

Pulmonary fibrosis is the end result of a variety of insults to the lung. Antecedent injuries to the lung may be recognized, as with chemotherapy [1], collagen vascular disease [2], or inhalational injury [3]. However, in idiopathic pulmonary fibrosis (IPF) [also termed cryptogenic fibrosing alveolitis (CFA)], the inciting insult remains unidentified. In 1969, Liebow and Carrington first classified interstitial pneumonias into five distinct categories, based on histological features [4] (Table 1). Subsequently, giant cell interstitial pneumonia (GIP) was excluded from the category of IPF because GIP is the histological manifestation of hardmetal pneumoconiosis [5]. The classification scheme of interstitial lung diseases has undergone numerous revisions and currently, seven distinct subtypes of idiopathic interstitial pneumonia (IIP) have been proposed by the American Thoracic Society/European Respiratory Society (ATS/ERS): usual interstitial pneumonia (UIP), desquamative interstitial pneumonia (DIP), respiratory bronchiolitis interstitial lung disease (RB-ILD), acute interstitial pneumonia (AIP), non-specific interstitial pneumonia (NSIP), cryptogenic organizing pneumonia (COP), and lymphoid interstitial pneumonia (LIP) (Table 2) [6]. Of these histopathological subtypes, UIP is the histological pattern that characterizes patients with the clinical entity of IPF [6]. Based on the high proportion of UIP/IPF among the IIPs, its overall poor prognosis, and its unresponsiveness to currently available therapy, the remainder of this review will focus on mechanisms of fibrosis associated with UIP/IPF.

\section{Epidemiology and clinical features of IPF}

\section{Epidemiology}

IPF is a relatively rare disease, although the true prevalence is unknown. Prevalence rates of three to six cases per 100000 population are often cited [7], but a recent study in Finland demonstrated a nationwide prevalence of 16-18 per 100000 [8]. Subgroup analyses demonstrate a higher prevalence of IPF among older individuals. In one study, the prevalence of IPF was 2.7 per 100000 population among adults between age 35 and 44 years but rose to 175 per 100000 population in individuals older than 75 years [9]. The mean age at diagnosis of IPF is 66 years $[7,10]$. IPF is more common in males than in females and some studies indicate that an environmental or occupational exposure to dusts, organic solvents, or urban pollution increases the risk of developing IPF [7,11,12]. 
Table I. Original classification of interstitial pneumonia (Liebow)*

Bronchiolitis obliterans with interstitial pneumonia (BIP)

Desquamative interstitial pneumonia (DIP)

Giant cell interstitial pneumonia (GIP)

Lymphoid interstitial pneumonia (LIP)

Usual interstitial pneumonia (UIP)

* Adapted from ref 4 .

Table 2. New classification of idiopathic interstitial pneumonias (ATS/ERS)*

Acute interstitial pneumonia (AIP)

Cryptogenic organizing pneumonia (COP)

Desquamative interstitial pneumonia (DIP)

Respiratory bronchiolitis-interstitial lung disease (RB-ILD)

Lymphoid interstitial pneumonia (LIP)

Non-specific interstitial pneumonia (NSIP)

Usual interstitial pneumonia (UIP)

* Adapted from ref 6 .

Recently, data have emerged linking both genetic and environmental factors to the development of UIP/IPF. A familial form of UIP has been reported in $0.5-2.2 \%$ of cases [13] and a number of candidate genes encoding both cytokines and structural proteins have been identified in large kindreds [14,15]. Using linkage analysis, Thomas et al demonstrated a mutation in the pro-surfactant protein-C (proSP-C) gene encoding a leucine $\rightarrow$ glutamine substitution in the C-terminus [14]. This mutation results in improper intracellular trafficking of proSP-C in type II alveolar epithelial cells, as evidenced by electron microscopy showing aberrant subcellular localization of the protein and abnormal lamellar bodies [14]. These findings suggest that in this kindred, improper cellular processing of proSP-C may contribute to pulmonary fibrosis.

Pantelidis et al evaluated single nucleotide polymorphisms (SNPs) in four pro-inflammatory genes of 74 unrelated patients with clinical or biopsy-proven CFA [15]. Candidate genes included tumour necrosis factor- $\alpha$ (TNF- $\alpha)$, lymphotoxin- $\alpha$ (LT $\alpha)$, high affinity TNF- $\alpha / \mathrm{LT} \alpha$ receptor 2 (TNF-RII), and interleukin6 (IL-6). Although no difference existed between patients and controls with respect to genotype, allele, or haplotype frequencies, a strong association between carriage of the IL-6 (intron $4 \mathrm{G}$ ) allele and the TNFRII (1690C) allele was observed in patients, but not in controls [15]. Additionally, these investigators identified a strong linkage between the IL-6 (intron 4GG) genotype and disease progression as measured by diffusion capacity for carbon monoxide $\left(\mathrm{DL}_{\mathrm{CO}}\right)$, suggesting that progression of disease may be associated with decreased production of IL-6 [15].

Data implicating the major histocompatibility (HLA) system are sparse. In one study, Fulmer et al found no difference when comparing 35 separate antigens of the HLA-A and HLA-B loci in 33 patients with IPF with 329 healthy controls [16]. However, Libby et al identified an increase in HLA-DR2 in patients with IPF compared with controls [17]. It should be noted that both of these studies were performed at a time when the term 'IPF' encompassed many different histopathological entities and may not be representative of UIP/IPF.

Environmental factors have also been thought to contribute to the development of pulmonary fibrosis. In 1977, Millar reported a case of infectious mononucleosis in a woman with pulmonary fibrosis [18]. Since that time, numerous investigators have evaluated a possible link between viral infection and pulmonary fibrosis. Egan et al first demonstrated evidence of Epstein-Barr virus (EBV) replication in lower respiratory tract epithelial cells of patients with CFA [19]. Yonemaru et al subsequently showed increases in both cytomegalovirus (CMV) and EBV viral capsid antigen IgG and complement fixation titres in patients with IPF and connective tissue disease-related pulmonary fibrosis (CTD-PF) compared with controls or with patients with sarcoidosis or emphysema [20]. However, Wangoo et al evaluated the presence of EBV RNA and DNA in lung biopsy specimens from 12 patients with CFA compared with biopsy specimens from three normal controls and 12 patients with other diffuse lung diseases [21]. These investigators reported no difference in EBV antibody staining between patients and controls, no evidence for EBV RNA by in situ hybridization in any patient, and no difference in EBV DNA by polymerase chain reaction (PCR) [21]. This supports their conclusion that EBV infection is not associated with CFA. In contrast, Stewart et al observed that lung biopsy specimens from 12 of 27 (44\%) patients with IPF stained positively for EBV compared with 3 of 28 (10\%) controls $(p=0.005)$ [22]. Additionally, 13 IPF patients $(48 \%)$ but only four controls $(14 \%)$ were EBV-positive by PCR ( $p=0.007)$ [22]. These investigators subsequently showed that a rearrangement of EBV DNA termed EBV WZhet was associated with active EBV replication and was found in the peripheral blood of $16 / 27$ (59\%) IPF patients compared with $0 / 26(0 \%)$ lung transplant recipients and 1/24 (4\%) normal blood donors [23]. This suggested an association between this DNA rearrangement pattern and IPF.

Together, these data suggest a potential link between genetic or environmental factors that may predispose to the development of UIP/IPF in a subset of patients.

\section{Clinical features}

Patients with IPF typically complain of a dry, nonproductive cough and dyspnoea. Dyspnoea is often associated with exertion early in the disease course, but usually progresses to shortness of breath at rest [24]. On physical examination, bi-basilar, end-expiratory rales are appreciated in greater than $80 \%$ of patients [25]. Clubbing is noted in up to half of all patients [7]. Late in the course of the disease, cyanosis of the lips and fingers as well as signs of pulmonary hypertension may be seen [26]. Laboratory evaluation of patients 
with suspected UIP is primarily to rule out alternative causes of interstitial lung disease, such as sarcoidosis or CTD-PF. There are no laboratory tests specific for the diagnosis of UIP.

Restrictive pulmonary physiology is the classic finding on pulmonary function testing in IPF [27]. When a patient has concurrent emphysema, lung volumes may be relatively preserved [28]; however, the $\mathrm{DL}_{\mathrm{CO}}$ is disproportionately reduced [29]. Severe derangements in $\mathrm{DL}_{\mathrm{CO}}(<45 \%)$ and $\mathrm{VC}(<50 \%)$ are associated with increased mortality [30].

Greater than $90 \%$ of patients with UIP will have abnormal chest radiographs at the time of diagnosis [7]. The characteristic pattern is diffuse bilateral interstitial or reticulonodular infiltrates, most common in the basilar and subpleural regions of the lung [31]. Pleural disease and lymphadenopathy are rare and suggest an alternative diagnosis. Similar radiographic findings may be seen in secondary causes of pulmonary fibrosis including pneumoconioses and CTDPF [32].

High-resolution CT (HRCT) scanning has revolutionized the diagnostic evaluation of patients with suspected UIP. HRCT uses thin sections (1-2 mm slices) with special reconstruction of images that allows for enhanced visualization of lung parenchyma. Patterns typically seen include coarse reticular or linear opacities (intralobular and interlobular septal thickening) with a predilection for the periphery and lower lobes of the lungs, honeycomb cysts, and traction bronchiectasis [33]. Ground glass opacities (ill-defined hazy zones representing active alveolitis or fibrosis of the intralobular and alveolar septae) can be present; if they are the predominant pattern, it may indicate another subtype of IIP $[34,35]$. Extensive honeycombing, septal thickening, and a lack of ground glass opacities reflect a poor prognosis.

Diagnostic certainty of IPF is improved with a surgical lung biopsy showing a UIP pattern. Transbronchial lung biopsies usually do not allow for distinction among the various idiopathic interstitial pneumonias because of the limitations of the small biopsy size. Video-assisted thoracoscopic surgical (VATS) biopsy is the preferred method of obtaining lung tissue, as this procedure offers a similar yield to open thoracotomy [36]; VATS can be performed with relative ease and decreased morbidity [37].

\section{Histopathology}

UIP typically demonstrates a heterogeneous appearance, on low-power magnification, of normal-appearing lung alternating with areas of peripheral fibrosis, interstitial inflammation, and honeycomb changes [25], the so-called 'temporal heterogeneity' that is a hallmark of the disease (Figure 1). The inflammatory component is typically mild and consists primarily of lymphocytes and plasma cells. Other inflammatory cells such as neutrophils and eosinophils may be present, but are not abundant. Dense, relatively acellular, collagen bundles with smooth muscle metaplasia can be seen on higher-power magnification. At the border between fibrotic and normal lung are collections of fibroblasts/myofibroblasts, termed fibroblastic foci, that are thought to represent the active lesion of UIP (Figure 2) [38]. Alveolar epithelial injury with hyperplastic type II pneumocytes is often seen at areas of active fibrosis [39]. Honeycomb changes are depicted by enlarged, cystic airspaces lined by hyperplastic type II pneumocytes.

The presence of fibroblastic foci may be an important prognostic factor in IPF/UIP. Nicholson et al devised a semi-quantitative scoring system which grades four separate histological features (on a scale from 0 to 6): extent of fibroblastic foci, extent of interstitial mononuclear infiltrates, extent of established

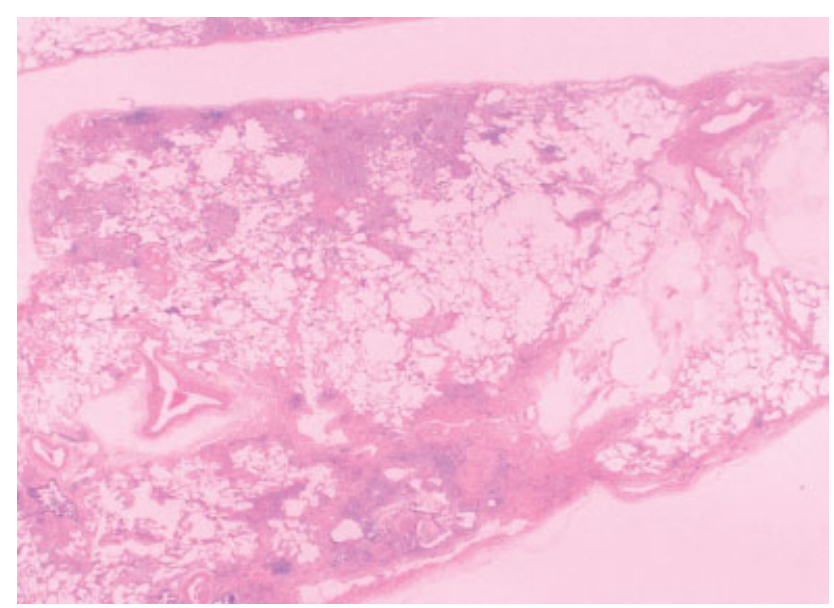

Figure I. Histopathology of UIP (low power). H\&E-stained whole mount section of lung from a patient with IPF. Note the characteristic peripheral, subpleural location of fibrosis and honeycomb change. These changes are heterogeneous, with regions of lung parenchyma spared from fibrosis

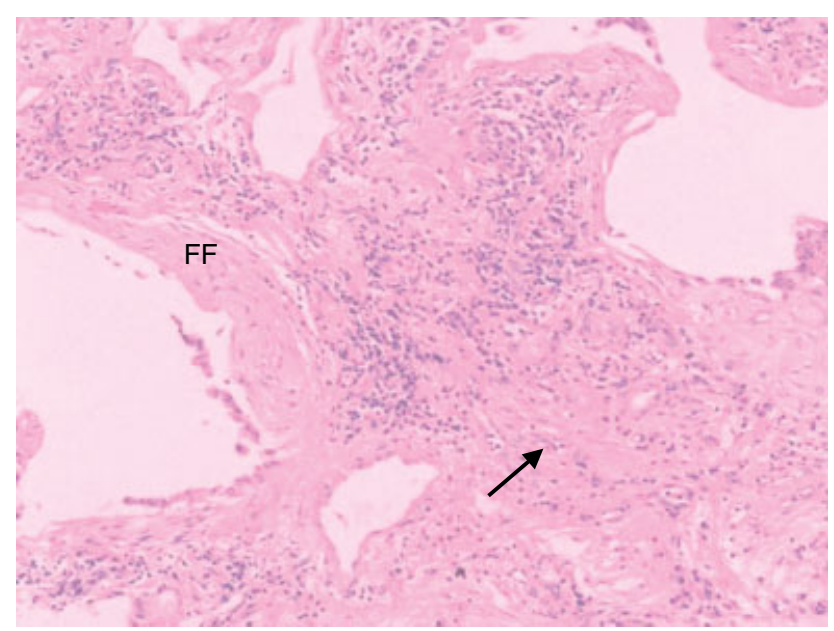

Figure 2. Histopathology of UIP (higher power). A hallmark of UIP is the heterogeneity, represented by dense, acellular bundles of collagen with smooth muscle metaplasia (arrow) in close approximation to the fibroblastic focus (FF), a dense collection of fibroblasts and myofibroblasts. Cuboidal epithelial cells lining distorted airspaces (which may be undergoing apoptosis) are seen overlying the fibroblastic focus 
fibrosis, and extent of intra-alveolar macrophage accumulation [40]. These investigators showed that extent of fibroblastic foci strongly correlated with decreased Forced Vital Capacity (FVC) and $\mathrm{DL}_{\mathrm{CO}}$ as well as mortality [40]. These data are in agreement with those of King et al, who devised a separate semi-quantitative scoring system to evaluate surgical lung biopsies of patients with UIP [41]. Biopsy scores were obtained for 14 histopathological features, which culminated in the derivation of four factor scores: the 'fibrosis factor', the 'cellularity factor', the 'alveolar space cellularity factor', and the 'granulation and young connective tissue factor' [41]. Controlling for age, gender, and smoking status, these researchers demonstrated that the granulation and young connective tissue score was a strong predictor of survival [41]. Together, these two studies suggest that the number of fibroblastic foci and the extent of granulation tissue and young connective tissue seen on surgical lung biopsies of patients with UIP/IPF may assist in predicting survival.

\section{Mechanisms of fibrogenesis}

\section{Alveolar epithelial cells (AECs): targets of early injury}

The normal alveolar basement membrane is lined with alveolar epithelial cells (AECs), which can be subdivided into type I and type II pneumocytes. Ninety-five per cent of the alveolar surface is covered with type I pneumocytes. These cells are metabolically active and harbour cell surface receptors for a variety of substances, including extracellular matrix (ECM) proteins, growth factors, and cytokines. The remaining $5 \%$ of alveolar lining cells consist of cuboidal epithelia (type II pneumocytes). Type II pneumocytes secrete surfactant, facilitate transepithelial movement of water, function as antigen presentation cells, and represent a reservoir of progenitor cells that regenerate the alveolar epithelium following lung injury [42].

It has been postulated that UIP may be the result of abnormal 'wound healing' of the alveolar epithelium after an injury [24,38]. In surgical lung biopsies of patients with UIP, morphological changes including hyperplastic type II cells, elongated type II cells, and bronchiolar cells lining areas of honeycomb lesions can be seen [43]. In addition, the apposition of denuded basement membrane and the obliteration of the airspace may result from lack of alveolar epithelial cell proliferation and differentiation [44]. Evidence for an altered AEC phenotype is also supported by data demonstrating that AECs from patients with UIP synthesize a different set of cytokeratins than AECs from normal lung [45]. Epithelial cell function is often determined by the type of cytokeratin expression; thus, AECs in UIP may have both different form and function when compared with alveolar epithelial cells in normal lung.

Biopsy specimens of patients with UIP often demonstrate areas of denuded alveolar basement membrane.
This implies either an increase in AEC death (necrosis or apoptosis), a lack of proliferative capacity of AECs, or a combination of both processes. Uhal et al demonstrated that myofibroblasts from patients with fibrotic lung disease secrete soluble factor(s) that induce apoptosis of human AECs [46]. A follow-up study from this same group of investigators showed that angiotensin II accounted for the majority of this effect; the addition of angiotensin II antibodies or receptor antagonists prevented fibrotic-lung fibroblasts from inducing apoptosis in AECs [47]. Other evidence for AEC apoptosis in the pathogenesis of UIP is provided by Maeyama et al, who demonstrated an up-regulation of the pro-apoptotic Fas-Fas ligand system in AECs from patients with pulmonary fibrosis [48].

Classically, local expansion of type II AECs following lung injury was thought to re-populate denuded alveolar basement membranes in response to growth factors such as hepatocyte growth factor and keratinocyte growth factor [43]. Recent data from animal models of lung injury also suggest that bone marrowderived progenitor cells can differentiate into type I AECs $[49,50]$, suggesting an additional mechanism for re-epithelialization of damaged alveoli. However, this mechanism has not yet been demonstrated in humans and further studies are needed to determine whether human bone marrow-derived cells possess the capacity to transdifferentiate into alveolar epithelium.

In the normal alveolus, an intact AEC lining may exert a homeostatic effect on local fibroblasts/mesenchymal cells. A discontinuous and/or damaged layer of AECs, as in patients with UIP, may induce the secretion of stimulatory molecules or result in diminished synthesis of inhibitory factors. Prostaglandin E2 $\left(\mathrm{PGE}_{2}\right)$ is a potent inhibitor of fibroblast collagen synthesis and proliferation $[51,52]$. In broncho-alveolar lavage (BAL) fluid from patients with UIP, PGE $_{2}$ levels have been shown to be approximately half those of control patients [53], suggesting that loss of AECs or the diminished capacity of AECs to synthesize $\mathrm{PGE}_{2}$ may contribute to the pro-fibrotic milieu in the alveolar space.

In addition to prostanoids, AECs also synthesize numerous growth factors and cytokines that activate fibroblasts/mesenchymal cells. AECs are the primary source for transforming growth factor-beta (TGF- $\beta$ ) [54], a critical cytokine in the transdifferentiation of fibroblasts into the activated myofibroblast phenotype. Additionally, AECs produce platelet-derived growth factor (PDGF) [55], tumour necrosis factor alpha (TNF- $\alpha)$ [56], and endothelin-1 [57]. PDGF is a potent mitogen and chemoattractant for fibroblasts; PDGF mRNA and protein have been shown to be upregulated in epithelial cells of patients with IPF [55]. TNF- $\alpha$ is secreted by hyperplastic type II AECs in pulmonary fibrosis $[56,58]$ and promotes DNA synthesis and proliferation of fibroblasts [59]. Endothelin-1 has also been shown to stimulate fibroblast DNA synthesis and proliferation as well as to induce transdifferentiation of fibroblasts to myofibroblasts [60]. 
AECs also likely contribute to the pathogenesis of UIP by regulating the plasminogen activation system. The plasminogen activation system is critical to normal wound healing [61]. Plasminogen, activated by tissue-type plasminogen activator (tPA) or urokinase-type plasminogen activator (uPA) to plas$\mathrm{min}$, is the primary fibrinolytic enzyme responsible for degrading fibrin clots and allowing for wound reepithelialization. Plasminogen, and thus plasmin activity, is negatively regulated by plasminogen activator inhibitors (PAIs). Animal models suggest that overexpression of PAIs (which inhibits plasmin activity) promotes fibrosis, whereas lack of PAIs (allowing greater plasmin activity) prevents the formation of significant fibrosis [62]. Additionally, overexpression of uPA was shown to decrease fibrosis in a murine model [63]. In UIP, the plasminogen activation system has been implicated in regulating fibrin turnover and ECM degradation [42]. It is known that AECs synthesize both PAI-1 and urokinase [64,65] as well as the urokinase receptor, uPAR [66]. Kotani et al showed that BAL fluid from patients with IPF contains significantly greater amounts of tissue factor and PAIs than normals, whereas uPA levels were similar between the two groups [67]. These studies suggest that the alveolar microenvironment in IPF favours a pro-coagulant, anti-fibrinolytic state that favours ECM accumulation and retards alveolar re-epithelialization.

\section{Fibroblasts/myofibroblasts: key effector cells in fibrogenesis}

Fibroblasts are the most versatile of the connectivetissue cell family and possess a remarkable capacity to undergo various phenotypic conversions between distinct but related cell types. This phenotypic plasticity is an important feature of the responses to many types of tissue injury [61]. Fibroblasts participate in repair and regenerative processes in almost every human tissue and organ. Their primary function is to secrete ECM proteins that provide a tissue scaffold for normal repair events such as epithelial cell migration. Eventual dissolution of this scaffold and apoptosis of fibroblasts/myofibroblasts are critical for restoration of normal tissue architecture $[68,69]$.

Fibroblasts with an activated myofibroblast phenotype have been described in the fibroblastic foci that characterize UIP [39,70]. Gabbiani et al first described the transient appearance and disappearance of these so-called myofibroblasts in the granulation tissue of healing cutaneous wounds [71]. Myofibroblasts possess ultrastructural features intermediate between fibroblasts and smooth muscle cells and have been defined by their ability to express contractile proteins [72]. This contractile function is important in the re-epithelialization process by bringing wound margins closer together. In addition, myofibroblasts represent an 'activated' fibroblast phenotype with high synthetic capacity for ECM proteins [73,74], growth factors/cytokines [75], growth factor receptors [76], integrins [77], and oxidants [78,79]. Persistence of myofibroblasts in areas of active fibrosis appears to be a consistent finding in the pathology of human fibrotic diseases involving diverse organ systems $[38,80]$.

Several studies have attempted to characterize the phenotype of fibroblasts in UIP/IPF. These studies have sometimes produced conflicting results, which may be related to inherent tissue fibroblast heterogeneity and changes in cellular microenvironment, including in vitro culture conditions. Fibroblasts derived from fibrotic tissue have been reported to demonstrate both high and low proliferative capacities [81-83]; lower rates appear to be associated with more advanced fibrosis [81]. Fibrotic lung fibroblasts demonstrate anchorage-independent growth in soft agar, whereas normal fibroblasts do not [84]. In vivo apoptotic rates of fibroblasts/myofibroblasts from UIP appear to be lower than those found in the fibromyxoid connective tissue of bronchiolitis obliterans organizing pneumonia [85]; paradoxically higher rates have been observed in in vitro culture of UIP fibroblasts [83]. The discrepancies in growth, apoptosis, and myofibroblast phenotype most likely reflect differences in culture technique, passage number, and inter-patient variability. Newer techniques, such as laser capture microdissection (LCM), have been proposed to address these inherent problems related to tissue heterogeneity [86]. Coupled with gene expression and protein expression arrays, LCM of fibroblastic foci fibroblasts will allow investigators to define the phenotype of the active lesion in UIP fully and more accurately.

UIP fibroblasts possess a highly synthetic phenotype and produce a number of ECM proteins and integrin molecules $[39,70,83,87,88]$. This is accompanied by imbalances in the production of matrix metalloproteinases (MMPs) and tissue inhibitors of metalloproteinases (TIMPs) [83,89]. In particular, TIMP-2 expression by UIP fibroblasts/myofibroblasts appears to contribute to the irreversible structural remodelling in this disease [90-92]. Myofibroblasts in UIP have been shown to secrete angiotensin peptides that may induce apoptosis of adjacent alveolar epithelial cells [46,47,93]. Other phenotypic characteristics described in UIP fibroblasts include enhanced migratory capacity [94], increased fibroblast contractility [95], and diminished cyclooxygenase-2 expression/prostaglandin E2 synthesis [96]. Moreover, fibroblasts themselves express surface receptors such as CD40 typically associated with immune cells and are capable of producing a number of chemokines and cytokines [97-99]. Thus, fibroblasts and myofibroblasts, with their variegated phenotypes and multiple roles, appear to be key effector cells in the pathogenesis of fibrosis. 
Neutrophils and other inflammatory cells: effector cell or bystander?

The role of neutrophils and other inflammatory cells such as eosinophils, mast cells, and lymphocytes in the pathogenesis of IPF is largely unknown. Neutrophils have been more extensively studied in pulmonary fibrosis than other inflammatory cells, but data demonstrating an active role for these cells in the late stages of UIP/IPF are scant. A number of studies have demonstrated an association between the presence of inflammatory cells and disease [100-107]; however, the precise cause-effect relationship is unclear.

Neutrophils circulate in blood as quiescent cells and express small quantities of surface proteins that serve as adhesion molecules [108]. Once recruited to sites of injury, neutrophils undergo a variety of functional changes affecting cellular adhesion, transmigration, and the release of toxic products. Neutrophils contain a large number of hydrolytic enzymes and other toxic molecules in their granules, including neutrophil elastase, lysozyme, myeloperoxidase, and members of the MMP family [109]. In addition, these cells can generate various oxidant species, including superoxide anion $\left(\mathrm{O}_{2}{ }^{-}\right)$, hydrogen peroxide $\left(\mathrm{H}_{2} \mathrm{O}_{2}\right)$, and hypochlorous acid (HOCl) [110,111]. Extracellular release of these toxic substances can result in lung parenchymal and stromal cell injury, as well as degradation of key ECM components of lung tissue. In addition to elastin, neutrophil elastase can degrade collagen types III and IV, laminin, fibronectin, and core proteins of proteoglycans [112]. Furthermore, elastase can cleave pro-enzyme forms of MMPs into the fully active form of these enzymes [113]. Elastase burden was found to be increased in BAL fluid from patients with IPF [107], suggesting a potential role for this protease in the pathogenesis of IPF.

Of the enzymes found in neutrophil granules, MMPs (notably MMP-2 and MMP-9) have been most closely linked with degradation of ECM components in UIP [89,91]. Exuberant expression of neutrophil-derived serine proteinases and MMPs has also been observed in the airspace and lung interstitium of patients with IPF $[91,114]$. These proteases may propagate abnormal tissue remodelling in IPF by damage to alveolar basement membranes. An alternative hypothesis suggests that enhanced protease expression may be overly compensated for by even greater expression of TIMPs and other anti-proteases in the lung interstitium of IPF patients, which would have the net effect of diminished proteolytic activity and progressive ECM accumulation. In support of this concept, Selman et al observed that IPF lungs display increased TIMP expression compared with MMP expression, suggesting an imbalance between MMPs and TIMPs [89].

In addition to proteolytic enzymes, the neutrophil is an important source of reactive oxygen species [111]. Nicotinamide adenine dinucleotide phosphate
(NADPH)-oxidase is the predominant enzyme responsible for oxidant production. Upon neutrophil activation, $\mathrm{NADPH}$-oxidase generates $\mathrm{O}_{2}{ }^{--}$, which dismutates to $\mathrm{H}_{2} \mathrm{O}_{2}$. Neutrophil-derived myeloperoxidase then catalyses the conversion of $\mathrm{H}_{2} \mathrm{O}_{2}$, a relatively weak oxidant, into the more potent oxidant $\mathrm{HOCl}$ [115]. $\mathrm{HOCl}$ and other oxidants may directly convert pro-metalloproteinases into active enzymes [116], further altering the protease-anti-protease balance. Superoxide anion generated by activated neutrophils can also perpetuate tissue injury by reacting with nitric oxide released by neutrophils, macrophages, endothelial cells, and fibroblasts to form the highly reactive species peroxynitrite and peroxynitrous acid [117]. These metabolites can induce lipid peroxidation in vitro; enhanced peroxynitrite activity has been observed in the lungs of patients with IPF [118]. Furthermore, oxidants produced by neutrophils and myofibroblasts may mediate cross-linking of ECM proteins that contribute to the remodelling process [119]. Finally, reactive oxygen species can further amplify neutrophilic inflammation and injury by activating key cellular transcription factors, including NF- $\kappa \mathrm{B}$, AP1 , and JAK-STAT, critical for the activation of proinflammatory and pro-fibrotic genes [120,121].

It remains possible that neutrophils do not play an active role in the pathogenesis of IPF, but might instead be 'bystander' cells recruited in response to mediators released during the fibrotic response. Notably, a family of chemotactic cytokines, referred to as CXC chemokines, exerts potent neutrophil chemoattractant activity and are critical mediators of angiogenesis [122]. In human pulmonary fibrosis, the CXC chemokine family, which consists of both angiogenic and angiostatic molecules, is thought to be important in influencing angiogenesis [123,124]. It has been shown that the expression of the neutrophil chemotactic CXC chemokines interleukin8 (IL-8/CXCL8) and epithelial neutrophil-activating peptide (ENA)-78/CXCL5 is markedly increased in the BAL fluid and cells isolated from patients with UIP, compared with patients with sarcoidosis or normal volunteers [125]. IL-8/CXCL8 mRNA expression positively correlated with the degree of BAL neutrophilia. However, there was a distinct lack of neutrophilic infiltration in areas of lung where ENA78/CXCL5 was expressed, suggesting a role for ENA78/CXCL5 in UIP that is distinct and separate from neutrophil chemotactic effects [124]. Similarly, in a murine model of bleomycin-induced pulmonary fibrosis, these investigators demonstrated that macrophage inflammatory protein (MIP)-2, the murine functional homologue of IL-8 [126], mediates angiogenesis but not neutrophil recruitment [127]. Specifically, neutralization of MIP-2 activity resulted in decreased angiogenesis and attenuated pulmonary fibrosis, but had no effect on the influx of neutrophils into the lung, again suggesting that the neutrophil chemoattractant properties and angiogenic properties of the CXC chemokine family may be quite distinct. 
It should be noted that the role of angiogenesis in the development of UIP/IPF remains controversial. Angiogenesis is required for initiation of wound healing and formation of granulation tissue [128]. However, as scar tissue matures, there is an ordered regression of vessels with deposition of collagen and contraction of the wound bed by myofibroblasts [128]. In support of the wound healing model of UIP/IPF, Renzoni et al recently observed a net vascular regression in lung biopsy specimens from patients with CFA or with fibrosing alveolitis associated with systemic sclerosis, compared with control samples [129]. These investigators demonstrated decreased vascular density as well as decreased total vascular area in specimens of CFA compared with normals. This finding is in agreement with the earlier findings of Cassan et al, who identified decreased mean capillary surface area in nine patients with CFA compared with normal controls [130].

Eosinophils were first postulated to be involved in the pathogenesis of IPF in 1977, when Reynolds et al demonstrated a significant increase in BAL fluid eosinophils from patients with pulmonary fibrosis compared with controls [103]. Further investigation revealed that a higher eosinophil count in BAL fluid predicted failure to respond to corticosteroid therapy and a greater likelihood of disease progression [131]. Elevated eosinophil counts and increased levels of an eosinophil-specific protein (eosinophil cationic protein, ECP) in BAL fluid have been shown by other investigators [132,133], but the role of eosinophils in fibrogenesis remains obscure. Wells et al compared BAL fluid cellularity from patients with IPF and patients with scleroderma-associated pulmonary fibrosis. These investigators observed that eosinophil counts were higher in patients with IPF than in patients with scleroderma, suggesting that eosinophils might play a pathogenetic role in IPF and contribute to a worse prognosis [101].

Mast cells have been found in increased numbers in biopsy specimens of patients with IPF [134,135]. In addition, mast cell products, notably mast cell tryptase and histamine, have been recovered from the BAL fluid of patients with IPF [136]. Ultrastructurally, on electron microscopy, mast cells in tissue specimens of IPF show evidence of degranulation [137] and close apposition to fibroblasts [138], suggesting a potential role for mast cells in the pathogenesis of UIP. Incomplete degranulation on electron microscopy suggests a chronic 'piecemeal' degranulation process which contrasts with the total degranulation observed in anaphylaxis [139]. This 'piecemeal' degranulation may result in ongoing tissue injury that promotes fibrosis.

\section{Therapeutic options for pulmonary fibrosis}

Currently, no effective treatment for IPF exists. Therapeutic options for IPF have traditionally focused on the paradigm that chronic inflammation leads to tissue injury and fibrosis; thus, corticosteroids have been considered the mainstay of treatment for

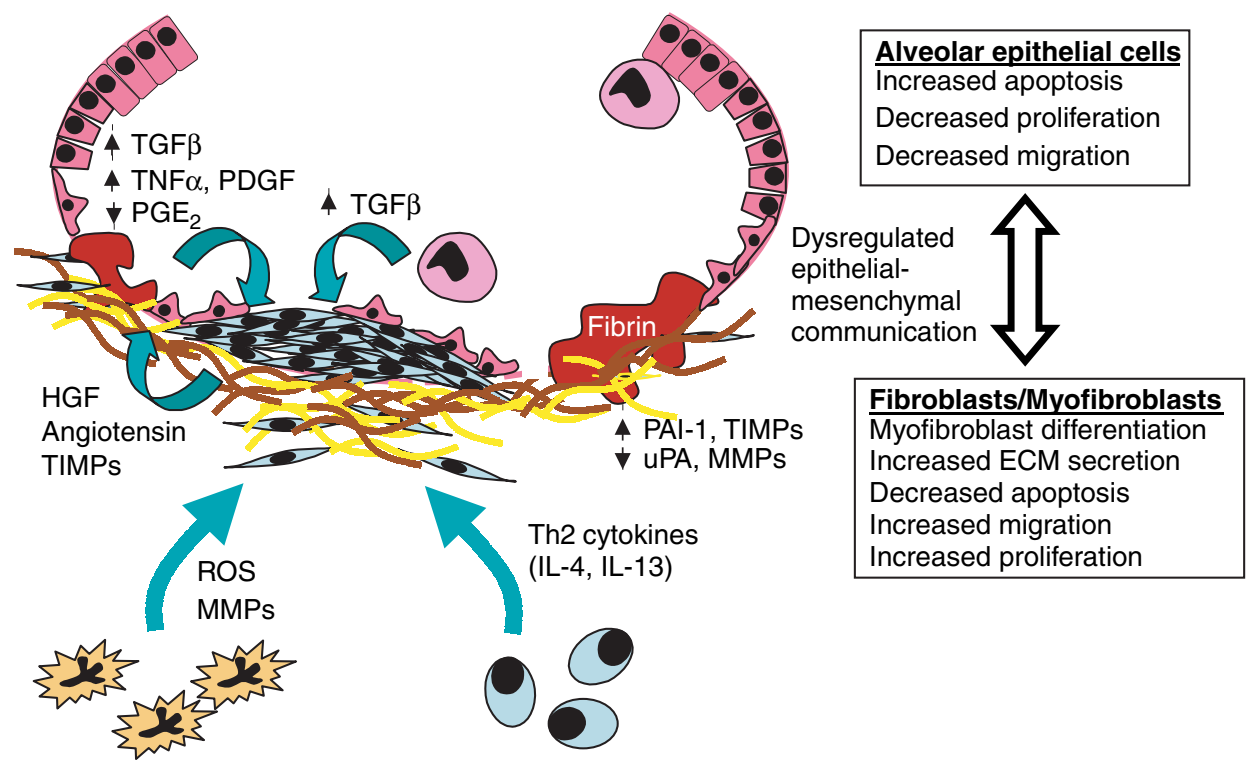

Figure 3. Overview of some of the key pathogenetic mechanisms in UIP/IPF. Following an unidentified insult, alveolar epithelial cells become injured and delayed re-epithelialization leads to a denuded, disrupted basement membrane. A fibrin clot forms early and serves as a provisional matrix for the migration and proliferation of reparative type I alveolar epithelial cells. Angiogenic factors may be elaborated, leading to the formation of nascent vasculature early in the disease process. Neutrophils secrete pro-inflammatory mediators, reactive oxygen species (ROS) and MMPs, while recruited lymphocytes elaborate the Th2-type cytokines, IL-4 and IL-I3. Fibroblasts migrate into the wound and produce extracellular matrix (ECM) proteins and mediators such as angiotensin II which may further promote alveolar epithelial cell apoptosis. Alveolar macrophages and epithelial cells secrete TGF- $\beta$ I, which promotes myofibroblast differentiation, increases ECM production, and inhibits apoptosis of fibroblasts/myofibroblasts. As ECM deposition progresses, regression of blood vessels may occur. Reciprocal communication between alveolar epithelial cells and mesenchymal cells results in a 'positive feedback loop' that promotes ongoing fibrosis and destruction of alveolar architecture 
IPF. However, no prospective, randomized, placebocontrolled trials evaluating their efficacy in the treatment of IPF have been performed [25] and recent data suggest that corticosteroids may be harmful rather than beneficial in these patients [140]. Regimens containing other immunosuppressive and cytotoxic agents, such as cyclophosphamide [141], azathioprine [142], and colchicine [143], have been used but confer no benefit compared with steroids alone or, in some cases, placebo alone. A newer anti-fibrotic agent, pirfenidone, has been proposed in patients with IPF [144]; a phase III, randomized, multi-centre trial with this agent is planned. Interferon- $\gamma$ has also been shown to have promising effects in the treatment of IPF, although a preliminary study showing efficacy included only 18 patients (nine who received prednisolone and nine who received prednisolone plus interferon- $\gamma$ [145]. Additionally, in this pilot study, survival benefits were not assessed. Recently, a phase III, double-blinded placebo controlled multi-centre randomized trial of interferon- $\gamma$ in IPF was completed, but the results of this trial have not yet been published.

\section{Conclusion}

IPF is a progressive, fibrotic process of the distal airspaces and interstitium of the lung that is characterized by the histological pattern of usual interstitial pneumonia (UIP). Therapy for this disease with glucocorticoids and other immunomodulatory agents is largely ineffective. UIP is not associated with a significant inflammatory response; rather, it appears to result from dysregulated epithelial-mesenchymal communication (Figure 3 ). Only recently have we begun to identify some of the key intracellular pathways and mediators that play a role in the pathogenesis of UIP $[146,147]$. As our understanding of the pathogenetic mechanisms in UIP/IPF increases, the development of more targeted approaches that interfere with fibrogenesis will help to combat this progressive, disabling and fatal disease.

\section{Acknowledgements}

Dr White is supported by grants from the National Institutes of Health (K08 HL70990), the American Lung Association (DA-004-N), and the Pulmonary Fibrosis Foundation. Dr Thannickal is supported by National Institutes of Health grant R01 HL67967.

\section{References}

1. Segura A, Yuste A, Cercos A, et al. Pulmonary fibrosis induced by cyclophosphamide. Ann Pharmacother 2001; 35: 894-897.

2. Lynch JP III, Hunninghake GW. Pulmonary complications of collagen vascular disease. Annu Rev Med 1992; 43: 17-35.

3. De Vuyst P, Camus P. The past and present of pneumoconioses. Curr Opin Pulm Med 2000; 6: 151-156.

4. Liebow AA, Carrington CB. The interstitial pneumonias. In Frontiers of Pulmonary Radiology. (1st edn), Simon M,
Potchen EJ, LeMay M (eds). Grune \& Stratton: New York, 1969; $102-141$.

5. Katzenstein AL, Myers JL. Idiopathic pulmonary fibrosis: clinical relevance of pathologic classification. Am J Respir Crit Care Med 1998; 157: 1301-1315.

6. American Thoracic Society/European Respiratory Society International Multidisciplinary Consensus Classification of the Idiopathic Interstitial Pneumonias. This joint statement of the American Thoracic Society (ATS), and the European Respiratory Society (ERS) was adopted by the ATS Board of Directors, June 2001 and by the ERS Executive Committee, June 2001. Am J Respir Crit Care Med 2002; 165: 277-304.

7. Johnston ID, Prescott RJ, Chalmers JC, Rudd RM. British Thoracic Society study of cryptogenic fibrosing alveolitis: current presentation and initial management. Fibrosing Alveolitis Subcommittee of the Research Committee of the British Thoracic Society. Thorax 1997; 52: 38-44.

8. Hodgson U, Laitinen T, Tukiainen P. Nationwide prevalence of sporadic and familial idiopathic pulmonary fibrosis: evidence of founder effect among multiplex families in Finland. Thorax 2002; 57: $338-342$.

9. Coultas DB, Zumwalt RE, Black WC, Sobonya RE. The epidemiology of interstitial lung diseases. Am J Respir Crit Care Med 1994; 150: 967-972.

10. Carrington C, Gaensler E, Coutu R, Fitzgerald MX, Gupta R. Natural history and treated course of usual and desquamative interstitial pneumonia. N Engl J Med 1978; 298: 801-809.

11. Hubbard R, Lewis S, Richards K, Johnston I, Britton J. Occupational exposure to metal or wood dust and aetiology of cryptogenic fibrosing alveolitis. Lancet 1996; 347: 284-289.

12. Iwai K, Mori T, Yamada N, Yamaguchi M, Hosoda Y. Idiopathic pulmonary fibrosis. Epidemiologic approaches to occupational exposure. Am J Respir Crit Care Med 1994; 150: 670-675.

13. Marshall RP, Puddicombe A, Cookson WO, Laurent GJ. Adult familial cryptogenic fibrosing alveolitis in the United Kingdom. Thorax 2000; 55: 143-146.

14. Thomas AQ, Lane K, Phillips J 3rd, et al. Heterozygosity for a surfactant protein $\mathrm{C}$ gene mutation associated with usual interstitial pneumonitis and cellular nonspecific interstitial pneumonitis in one kindred. Am J Respir Crit Care Med 2002; 165: $1322-1328$.

15. Pantelidis P, Fanning GC, Wells AU, Welsh KI, Du Bois RM. Analysis of tumor necrosis factor-alpha, lymphotoxin-alpha, tumor necrosis factor receptor II, and interleukin-6 polymorphisms in patients with idiopathic pulmonary fibrosis. Am J Respir Crit Care Med 2001; 163: 1432-1436.

16. Fulmer JD, Sposovska MS, von Gal ER, Crystal RG, Mittal KK. Distribution of HLA antigens in idiopathic pulmonary fibrosis. Am Rev Respir Dis 1978; 118: 141-147.

17. Libby DM, Gibofsky A, Fotino M, Waters SJ, Smith JP. Immunogenetic and clinical findings in idiopathic pulmonary fibrosis. Association with the B-cell alloantigen HLA-DR2. Am Rev Respir Dis 1983; 127: 618-622.

18. Millar JW. Infectious mononucleosis and fibrosing alveolitis. $\mathrm{Br}$ Med J 1977; 1: 612.

19. Egan JJ, Stewart JP, Hasleton PS, Arrand JR, Carroll KB, Woodcock AA. Epstein-Barr virus replication within pulmonary epithelial cells in cryptogenic fibrosing alveolitis. Thorax 1995; 50: $1234-1239$.

20. Yonemaru M, Kasuga I, Kusumoto H, et al. Elevation of antibodies to cytomegalovirus and other herpes viruses in pulmonary fibrosis. Eur Respir J 1997; 10: 2040-2045.

21. Wangoo A, Shaw RJ, Diss TC, Farrell PJ, du Bois RM, Nicholson AG. Cryptogenic fibrosing alveolitis: lack of association with Epstein-Barr virus infection. Thorax 1997; 52: 888-891.

22. Stewart JP, Egan JJ, Ross AJ, et al. The detection of EpsteinBarr virus DNA in lung tissue from patients with idiopathic pulmonary fibrosis. Am J Respir Crit Care Med 1999; 159: 1336-1341.

23. Kelly BG, Lok SS, Hasleton PS, Egan JJ, Stewart JP. A rearranged form of Epstein-Barr virus DNA is associated with 
idiopathic pulmonary fibrosis. Am J Respir Crit Care Med 2002; 166: $510-513$.

24. Crystal RG, Fulmer JD, Roberts WC, Moss ML, Line BR, Reynolds HY. Idiopathic pulmonary fibrosis. Clinical, histologic, radiographic, physiologic, scintigraphic, cytologic, and biochemical aspects. Ann Intern Med 1976; 85: 769-788.

25. American Thoracic Society. Idiopathic pulmonary fibrosis: diagnosis and treatment. International consensus statement. American Thoracic Society (ATS), and the European Respiratory Society (ERS). Am J Respir Crit Care Med 2000; 161: 646-664.

26. Panos R, Mortenson R, Niccoli S, King T. Clinical deterioration in patients with idiopathic pulmonary fibrosis: causes and assessment. Am J Med 1990; 88: 396-404.

27. Flaherty KR, Martinez FJ. The role of pulmonary function testing in pulmonary fibrosis. Curr Opin Pulm Med 2000; 6: 404-410.

28. Doherty MJ, Pearson MG, O'Grady EA, Pellegrini V, Calverley PM. Cryptogenic fibrosing alveolitis with preserved lung volumes. Thorax 1997; 52: 998-1002.

29. Wells A, King A, Rubens M, Cramer D, du Bois R, Hansell D. Lone cryptogenic fibrosing alveolitis: a functional-morphologic correlation base on extent of disease on thin section computed tomography. Am J Respir Crit Care Med 1997; 155: 1367-1375.

30. Erbes R, Schaberg T, Loddenkemper R. Lung function tests in patients with idiopathic pulmonary fibrosis. Are they helpful for predicting outcome? Chest 1997; 111: 51-57.

31. Guerry-Force ML, Muller NL, Wright JL, et al. A comparison of bronchiolitis obliterans with organizing pneumonia, usual interstitial pneumonia, and small airways disease. Am Rev Respir Dis 1987; 135: 705-712.

32. Grenier P, Valeyre D, Cluzel P, Brauner MW, Lenoir S, Chastang C. Chronic diffuse interstitial lung disease: diagnostic value of chest radiography and high-resolution CT. Radiology 1991; 179: $123-132$.

33. Kazerooni EA. High-resolution CT of the lungs. Am J Roentgenol 2001; 177: 501-519.

34. Kazerooni EA, Martinez FJ, Flint A, et al. Thin-section CT obtained at 10-mm increments versus limited three-level thinsection CT for idiopathic pulmonary fibrosis: correlation with pathologic scoring. Am J Roentgenol 1997; 169: 977-983.

35. Wells A, Hansell D, Rubens M, Cullinan P, Black C, DuBois R. The predictive value of appearances on thin-section computed tomography in fibrosing alveolitis. Am Rev Respir Dis 1993; 148: 1076-1082.

36. Miller JD, Urschel JD, Cox G, et al. A randomized, controlled trial comparing thoracoscopy and limited thoracotomy for lung biopsy in interstitial lung disease. Ann Thorac Surg 2000; 70: $1647-1650$.

37. Blewett CJ, Bennett WF, Miller JD, Urschel JD. Open lung biopsy as an outpatient procedure. Ann Thorac Surg 2001; 71: $1113-1115$.

38. Selman M, King TE, Pardo A. Idiopathic pulmonary fibrosis: prevailing and evolving hypotheses about its pathogenesis and implications for therapy. Ann Intern Med 2001; 134: 136-151.

39. Kuhn C, McDonald JA. The roles of the myofibroblast in idiopathic pulmonary fibrosis. Ultrastructural and immunohistochemical features of sites of active extracellular matrix synthesis. $\mathrm{Am}$ J Pathol 1991; 138: 1257-1265.

40. Nicholson AG, Fulford LG, Colby TV, du Bois RM, Hansell DM, Wells AU. The relationship between individual histologic features and disease progression in idiopathic pulmonary fibrosis. Am J Respir Crit Care Med 2002; 166: 173-177.

41. King TE Jr, Schwarz MI, Brown K, et al. Idiopathic pulmonary fibrosis: relationship between histopathologic features and mortality. Am J Respir Crit Care Med 2001; 164: 1025-1032.

42. Simon R. Alveolar epithelial cells in pulmonary fibrosis. In Pulmonary Fibrosis, Phan SH, Thrall RS (eds). Marcel Dekker: New York, 1995; 511-540.

43. Kasper M, Haroske G. Alterations in the alveolar epithelium after injury leading to pulmonary fibrosis. Histol Histopathol 1996; 11: 463-483.
44. Simon RH, Paine R 3rd. Participation of pulmonary alveolar epithelial cells in lung inflammation. J Lab Clin Med 1995; 126: $108-118$.

45. Iyonaga K, Miyajima M, Suga M, Saita N, Ando M. Alterations in cytokeratin expression by the alveolar lining epithelial cells in lung tissues from patients with idiopathic pulmonary fibrosis. $J$ Pathol 1997; 182: 217-224.

46. Uhal BD, Joshi I, True AL, et al. Fibroblasts isolated after fibrotic lung injury induce apoptosis of alveolar epithelial cells in vitro. Am J Physiol 1995; 269: L819-L828.

47. Wang R, Ramos C, Joshi I, et al. Human lung myofibroblastderived inducers of alveolar epithelial apoptosis identified as angiotensin peptides. Am J Physiol 1999; 277: L1158-L1164.

48. Maeyama T, Kuwano K, Kawasaki M, et al. Upregulation of Fas-signalling molecules in lung epithelial cells from patients with idiopathic pulmonary fibrosis. Eur Respir J 2001; 17: $180-189$.

49. Kotton DN, Ma BY, Cardoso WV, et al. Bone marrow-derived cells as progenitors of lung alveolar epithelium. Development 2001; 128: 5181-5188.

50. Krause DS, Theise ND, Collector MI, et al. Multi-organ, multilineage engraftment by a single bone marrow-derived stem cell. Cell 2001; 105: 369-377.

51. Goldstein R, Polgar P. The effect and interaction of bradykinin and prostaglandins on protein and collagen production by lung fibroblasts. J Biol Chem 1982; 257: 8630-8633.

52. Lama V, Moore BB, Christensen P, Toews GB, PetersGolden M. Prostaglandin E2 synthesis and suppression of fibroblast proliferation by alveolar epithelial cells is cyclooxygenase2-dependent. Am J Respir Cell Mol Biol 2002; 27: 752-758.

53. Borok Z, Gillissen A, Buhl R, et al. Augmentation of functional prostaglandin $\mathrm{E}$ levels on the respiratory epithelial surface by aerosol administration of prostaglandin E. Am Rev Respir Dis 1991; 144: 1080-1084.

54. Khalil N, O'Connor RN, Flanders KC, Unruh H. TGF-beta 1, but not TGF-beta 2 or TGF-beta 3 , is differentially present in epithelial cells of advanced pulmonary fibrosis: an immunohistochemical study. Am J Respir Cell Mol Biol 1996; 14: $131-138$.

55. Antoniades HN, Bravo MA, Avila RE, et al. Platelet-derived growth factor in idiopathic pulmonary fibrosis. J Clin Invest 1990; 86: $1055-1064$.

56. Kapanci Y, Desmouliere A, Pache JC, Redard M, Gabbiani G. Cytoskeletal protein modulation in pulmonary alveolar myofibroblasts during idiopathic pulmonary fibrosis. Possible role of transforming growth factor beta and tumor necrosis factor alpha. Am J Respir Crit Care Med 1995; 152: 2163-2169.

57. Giaid A, Michel RP, Stewart DJ, Sheppard M, Corrin B, Hamid Q. Expression of endothelin-1 in lungs of patients with cryptogenic fibrosing alveolitis. Lancet 1993; 341: 1550-1554.

58. Nash JR, McLaughlin PJ, Butcher D, Corrin B. Expression of tumour necrosis factor-alpha in cryptogenic fibrosing alveolitis. Histopathology 1993; 22: 343-347.

59. Battegay EJ, Raines EW, Colbert T, Ross R. TNF-alpha stimulation of fibroblast proliferation. Dependence on platelet-derived growth factor (PDGF) secretion and alteration of PDGF receptor expression. J Immunol 1995; 154: 6040-6047.

60. Shahar I, Fireman E, Topilsky M, et al. Effect of endothelin-1 on alpha-smooth muscle actin expression and on alveolar fibroblast proliferation in interstitial lung diseases. Int J Immunopharmacol 1999; 21: 759-775.

61. Martin P. Wound healing - aiming for perfect skin regeneration. Science 1997; 276: 75-81.

62. Eitzman DT, McCoy RD, Zheng X, et al. Bleomycin-induced pulmonary fibrosis in transgenic mice that either lack or overexpress the murine plasminogen activator inhibitor-1 gene. J Clin Invest 1996; 97: 232-237.

63. Sisson TH, Hanson KE, Subbotina N, Patwardhan A, Hattori N, Simon RH. Inducible lung-specific urokinase expression reduces fibrosis and mortality after lung injury in mice. Am J Physiol Lung Cell Mol Physiol 2002; 283: L1023-L1032. 
64. Simon RH, Gross TJ, Edwards JA, Sitrin RG. Fibrin degradation by rat pulmonary alveolar epithelial cells. Am J Physiol 1992; 262: L482-L488.

65. Gross TJ, Simon RH, Sitrin RG. Expression of urokinase-type plasminogen activator by rat pulmonary alveolar epithelial cells. Am J Respir Cell Mol Biol 1990; 3: 449-456.

66. Hasegawa T, Sorensen L, Dohi M, Rao NV, Hoidal JR, Marshall BC. Induction of urokinase-type plasminogen activator receptor by IL-1 beta. Am J Respir Cell Mol Biol 1997; 16: 683-692.

67. Kotani I, Sato A, Hayakawa H, Urano T, Takada Y, Takada A. Increased procoagulant and antifibrinolytic activities in the lungs with idiopathic pulmonary fibrosis. Thromb Res 1995; 77: 493-504.

68. Desmouliere A, Redard M, Darby I, Gabbiani G. Apoptosis mediates the decrease in cellularity during the transition between granulation tissue and scar. Am J Pathol 1995; 146: 56-66.

69. Lorena D, Uchio K, Costa AM, Desmouliere A. Normal scarring: importance of myofibroblasts. Wound Repair Regen 2002; 10: $86-92$

70. Kuhn C 3rd, Boldt J, King TE Jr, Crouch E, Vartio T, McDonald JA. An immunohistochemical study of architectural remodeling and connective tissue synthesis in pulmonary fibrosis. Am Rev Respir Dis 1989; 140: 1693-1703.

71. Gabbiani G, Ryan GB, Majne G. Presence of modified fibroblasts in granulation tissue and their possible role in wound contraction. Experientia 1971; 27: 549-550.

72. Walker GA, Guerrero IA, Leinwand LA. Myofibroblasts: molecular crossdressers. Curr Top Dev Biol 2001; 51: 91-107.

73. Ignotz RA, Massague J. Transforming growth factor-beta stimulates the expression of fibronectin and collagen and their incorporation into the extracellular matrix. J Biol Chem 1986; 261: 4337-4345.

74. Zhang K, Rekhter MD, Gordon D, Phan SH. Myofibroblasts and their role in lung collagen gene expression during pulmonary fibrosis. A combined immunohistochemical and in situ hybridization study. Am J Pathol 1994; 145: 114-125.

75. Finlay GA, Thannickal VJ, Fanburg BL, Paulson KE. Transforming growth factor-beta 1-induced activation of the ERK pathway/activator protein-1 in human lung fibroblasts requires the autocrine induction of basic fibroblast growth factor. $J$ Biol Chem 2000; 275: 27 650-27 656.

76. Thannickal VJ, Aldweib KD, Rajan T, Fanburg BL. Upregulated expression of fibroblast growth factor (FGF) receptors by transforming growth factor-beta1 (TGF-beta1) mediates enhanced mitogenic responses to FGFs in cultured human lung fibroblasts. Biochem Biophys Res Commun 1998; 251: 437-441.

77. Heino J, Ignotz RA, Hemler ME, Crouse C, Massague J. Regulation of cell adhesion receptors by transforming growth factorbeta. Concomitant regulation of integrins that share a common beta 1 subunit. J Biol Chem 1989; 264: 380-388.

78. Thannickal VJ, Fanburg BL. Activation of an $\mathrm{H}_{2} \mathrm{O}_{2}$-generating NADH oxidase in human lung fibroblasts by transforming growth factor beta 1. J Biol Chem 1995; 270: 30 334-30 338.

79. Thannickal VJ, Larios JM, Fanburg BL. $\mathrm{H}_{2} \mathrm{O}_{2}$ production by myofibroblasts is dependent on $\mathrm{Src}$ kinase(s) and actin cytoskeletal regulation. Chest 2001; 120: 32S-33S.

80. Border WA, Noble NA. Transforming growth factor beta in tissue fibrosis. N Engl J Med 1994; 331: 1286-1292.

81. Raghu G, Chen YY, Rusch V, Rabinovitch PS. Differential proliferation of fibroblasts cultured from normal and fibrotic human lungs. Am Rev Respir Dis 1988; 138: 703-708.

82. Jordana M, Schulman J, McSharry C, et al. Heterogeneous proliferative characteristics of human adult lung fibroblast lines and clonally derived fibroblasts from control and fibrotic tissue. Am Rev Respir Dis 1988; 137: 579-584.

83. Ramos C, Montano M, Garcia-Alvarez J, et al. Fibroblasts from idiopathic pulmonary fibrosis and normal lungs differ in growth rate, apoptosis, and tissue inhibitor of metalloproteinases expression. Am J Respir Cell Mol Biol 2001; 24: 591-598.
84. Torry DJ, Richards CD, Podor TJ, Gauldie J. Anchorageindependent colony growth of pulmonary fibroblasts derived from fibrotic human lung tissue. J Clin Invest 1994; 93: 1525-1532.

85. Lappi-Blanco E, Soini Y, Paakko P. Apoptotic activity is increased in the newly formed fibromyxoid connective tissue in bronchiolitis obliterans organizing pneumonia. Lung 1999; 177: $367-376$

86. Crystal RG, Bitterman PB, Mossman B, et al. Future research directions in idiopathic pulmonary fibrosis: summary of a National Heart, Lung, and Blood Institute working group. Am J Respir Crit Care Med 2002; 166: 236-246.

87. Fukuda Y, Basset F, Ferrans VJ, Yamanaka N. Significance of early intra-alveolar fibrotic lesions and integrin expression in lung biopsy specimens from patients with idiopathic pulmonary fibrosis. Hum Pathol 1995; 26: 53-61.

88. Kuhn C, Mason RJ. Immunolocalization of SPARC, tenascin, and thrombospondin in pulmonary fibrosis. Am J Pathol 1995; 147: 1759-1769.

89. Selman M, Ruiz V, Cabrera S, et al. TIMP-1, $-2,-3$, and -4 in idiopathic pulmonary fibrosis. A prevailing nondegradative lung microenvironment? Am J Physiol Lung Cell Mol Physiol 2000; 279: L562-L574.

90. Hayashi T, Stetler-Stevenson WG, Fleming MV, et al. Immunohistochemical study of metalloproteinases and their tissue inhibitors in the lungs of patients with diffuse alveolar damage and idiopathic pulmonary fibrosis. Am J Pathol 1996; 149: 1241-1256.

91. Fukuda Y, Ishizaki M, Kudoh S, Kitaichi M, Yamanaka N. Localization of matrix metalloproteinases-1, -2, and -9 and tissue inhibitor of metalloproteinase-2 in interstitial lung diseases. Lab Invest 1998; 78: 687-698.

92. Fukuda Y, Mochimaru H, Terasaki Y, Kawamoto M, Kudoh S. Mechanism of structural remodeling in pulmonary fibrosis. Chest 2001; 120: S41-S43.

93. Uhal BD, Joshi I, Hughes WF, Ramos C, Pardo A, Selman M. Alveolar epithelial cell death adjacent to underlying myofibroblasts in advanced fibrotic human lung. Am J Physiol 1998; 275: L1192-L1199.

94. Suganuma H, Sato A, Tamura R, Chida K. Enhanced migration of fibroblasts derived from lungs with fibrotic lesions. Thorax 1995; 50: 984-989.

95. Miki H, Mio T, Nagai S, et al. Fibroblast contractility: usual interstitial pneumonia and nonspecific interstitial pneumonia. Am J Respir Crit Care Med 2000; 162: 2259-2264.

96. Wilborn J, Crofford LJ, Burdick MD, Kunkel SL, Strieter RM, Peters-Golden M. Cultured lung fibroblasts isolated from patients with idiopathic pulmonary fibrosis have a diminished capacity to synthesize prostaglandin E2 and to express cyclooxygenase-2. $J$ Clin Invest 1995; 95: 1861-1868.

97. Brouty-Boye D, Pottin-Clemenceau C, Doucet C, Jasmin C, Azzarone B. Chemokines and CD40 expression in human fibroblasts. Eur J Immunol 2000; 30: 914-919.

98. Kaufman J, Graf BA, Leung EC, et al. Fibroblasts as sentinel cells: role of the CD40-CD40 ligand system in fibroblast activation and lung inflammation and fibrosis. Chest 2001; 120: $53 \mathrm{~S}-55 \mathrm{~S}$.

99. Buckley CD, Pilling D, Lord JM, Akbar AN, Scheel-Toellner D, Salmon M. Fibroblasts regulate the switch from acute resolving to chronic persistent inflammation. Trends Immunol 2001; 22: 199-204.

100. Turner-Warwick M, Haslam PL. The value of serial bronchoalveolar lavages in assessing the clinical progress of patients with cryptogenic fibrosing alveolitis. Am Rev Respir Dis 1987; 135: 26-34.

101. Wells AU, Hansell DM, Haslam PL, et al. Bronchoalveolar lavage cellularity: lone cryptogenic fibrosing alveolitis compared with the fibrosing alveolitis of systemic sclerosis. Am J Respir Crit Care Med 1998; 157: 1474-1482.

102. Line BR, Fulmer JD, Reynolds HY, et al. Gallium-67 citrate scanning in the staging of idiopathic pulmonary fibrosis: correlation and physiologic and morphologic features and bronchoalveolar lavage. Am Rev Respir Dis 1978; 118: 355-365. 
103. Reynolds HY, Fulmer JD, Kazmierowski JA, Roberts WC, Frank MM, Crystal RG. Analysis of cellular and protein content of broncho-alveolar lavage fluid from patients with idiopathic pulmonary fibrosis and chronic hypersensitivity pneumonitis. $J$ Clin Invest 1977; 59: 165-175.

104. Hunninghake GW, Gadek JE, Lawley TJ, Crystal RG. Mechanisms of neutrophil accumulation in the lungs of patients with idiopathic pulmonary fibrosis. J Clin Invest 1981; 68: 259-269.

105. O’Donnell K, Keogh B, Cantin A, Crystal RG. Pharmacologic suppression of the neutrophil component of the alveolitis in idiopathic pulmonary fibrosis. Am Rev Respir Dis 1987; 136: 288-292.

106. Nakao A, Hasegawa Y, Tsuchiya Y, Shimokata K. Expression of cell adhesion molecules in the lungs of patients with idiopathic pulmonary fibrosis. Chest 1995; 108: 233-239.

107. Obayashi Y, Yamadori I, Fujita J, Yoshinouchi T, Ueda N, Takahara J. The role of neutrophils in the pathogenesis of idiopathic pulmonary fibrosis. Chest 1997; 112: 1338-1343.

108. Dallegri F, Ottonello L. Tissue injury in neutrophilic inflammation. Inflamm Res 1997; 46: 382-391.

109. Borregaard N, Lollike K, Kjeldsen L, et al. Human neutrophil granules and secretory vesicles. Eur J Haematol 1993; 51: 187-198.

110. Tiku K, Tiku ML, Skosey JL. Interleukin 1 production by human polymorphonuclear neutrophils. J Immunol 1986; 136: 3677-3685.

111. Winterbourn C. Neutrophil oxidants: production and reactions. In Oxygen Radicals: Systemic Events and Disease Processes, Das D, Essma W (eds). Karger: Basel, 1990; 31-70.

112. Travis J. Structure, function, and control of neutrophil proteinases. Am J Med 1988; 84: 37-42.

113. Palmgren MS, deShazo RD, Carter RM, Zimny ML, Shah SV. Mechanisms of neutrophil damage to human alveolar extracellular matrix: the role of serine and metalloproteases. J Allergy Clin Immunol 1992; 89: 905-915.

114. Gomez DE, Alonso DF, Yoshiji H, Thorgeirsson UP. Tissue inhibitors of metalloproteinases: structure, regulation and biological functions. Eur J Cell Biol 1997; 74: 111-122.

115. Winterbourn CC. Myeloperoxidase as an effective inhibitor of hydroxyl radical production. Implications for the oxidative reactions of neutrophils. J Clin Invest 1986; 78: 545-550.

116. Ottonello L, Dapino P, Scirocco M, Dallegri F, Sacchetti C. Proteolytic inactivation of alpha-1-antitrypsin by human neutrophils: involvement of multiple and interlinked cell responses to phagocytosable targets. Eur J Clin Invest 1994; 24: $42-9$.

117. Schmidt HH. Walter U. NO at work. Cell 1994; 78: 919-925.

118. Saleh D, Barnes PJ, Giaid A. Increased production of the potent oxidant peroxynitrite in the lungs of patients with idiopathic pulmonary fibrosis. Am J Respir Crit Care Med 1997; 155: 1763-1769.

119. Larios JM, Budhiraja R, Fanburg BL, Thannickal VJ. Oxidative protein cross-linking reactions involving L-tyrosine in transforming growth factor-beta1-stimulated fibroblasts. J Biol Chem 2001; 276: $17437-17441$.

120. Simon AR, Rai U, Fanburg BL, Cochran BH. Activation of the JAK-STAT pathway by reactive oxygen species. Am J Physiol 1998; 275: C1640-C1652.

121. Kim SJ, Angel P, Lafyatis R, et al. Autoinduction of transforming growth factor beta 1 is mediated by the AP- 1 complex. Mol Cell Biol 1990; 10: 1492-1497.

122. White ES, Strieter R, Arenberg D. Chemokines as therapeutic targets in lung cancer. Curr Med Chem 2002; 2: 403-417.

123. Keane MP, Arenberg DA, Lynch JP 3rd, et al. The CXC chemokines, IL-8 and IP-10, regulate angiogenic activity in idiopathic pulmonary fibrosis. J Immunol 1997; 159: 1437-1443.

124. Keane MP, Belperio JA, Burdick MD, Lynch JP, Fishbein MC. Strieter RM. ENA-78 is an important angiogenic factor in idiopathic pulmonary fibrosis. Am J Respir Crit Care Med 2001; 164: 2239-2242.
125. Lynch JP 3rd, Standiford TJ, Rolfe MW, Kunkel SL, Strieter RM. Neutrophilic alveolitis in idiopathic pulmonary fibrosis. The role of interleukin-8. Am Rev Respir Dis 1992; 145: 1433-1439.

126. Wolpe SD, Sherry B, Juers D, Davatelis G, Yurt RW, Cerami A. Identification and characterization of macrophage inflammatory protein 2. Proc Natl Acad Sci U S A 1989; 86: 612-616.

127. Keane MP, Belperio JA, Moore TA, et al. Neutralization of the CXC chemokine, macrophage inflammatory protein-2, attenuates bleomycin-induced pulmonary fibrosis. J Immunol 1999; 162: 5511-5518.

128. Clark RA. Basics of cutaneous wound repair. J Dermatol Surg Oncol 1993; 19: 693-706.

129. Renzoni EA, Walsh DA, Salmon M, et al. Interstitial vascularity in fibrosing alveolitis. Am J Respir Crit Care Med 2003; 167: 438-443.

130. Cassan SM, Divertie MB, Brown AL Jr. Fine structural morphometry on biopsy specimens of human lung. 2. Diffuse idiopathic pulmonary fibrosis. Chest 1974; 65: 275-278.

131. Rudd RM, Haslam PL, Turner-Warwick M. Cryptogenic fibrosing alveolitis. Relationships of pulmonary physiology and bronchoalveolar lavage to response to treatment and prognosis. Am Rev Respir Dis 1981; 124: 1-8.

132. Hallgren R, Bjermer L, Lundgren R, Venge P. The eosinophil component of the alveolitis in idiopathic pulmonary fibrosis. Signs of eosinophil activation in the lung are related to impaired lung function. Am Rev Respir Dis 1989; 139: 373-7.

133. Fujimoto K, Kubo K, Yamaguchi S, Honda T, Matsuzawa Y. Eosinophil activation in patients with pulmonary fibrosis. Chest 1995; 108: 48-54.

134. Hunt LW, Colby TV, Weiler DA, Sur S, Butterfield JH. Immunofluorescent staining for mast cells in idiopathic pulmonary fibrosis: quantification and evidence for extracellular release of mast cell tryptase. Mayo Clin Proc 1992; 67: 941-948.

135. Pesci A, Bertorelli G, Gabrielli M, Olivieri D. Mast cells in fibrotic lung disorders. Chest 1993; 103: 989-996.

136. Walls AF, Bennett AR, Godfrey RC, Holgate ST, Church MK. Mast cell tryptase and histamine concentrations in bronchoalveolar lavage fluid from patients with interstitial lung disease. Clin Sci (Colch) 1991; 81: 183-188.

137. Kawanami O, Ferrans VJ, Fulmer JD, Crystal RG. Ultrastructure of pulmonary mast cells in patients with fibrotic lung disorders. Lab Invest 1979; 40: 717-734.

138. Heard BE, Dewar A, Corrin B. Apposition of fibroblasts to mast cells and lymphocytes in normal human lung and in cryptogenic fibrosing alveolitis. Ultrastructure and cell perimeter measurements. J Pathol 1992; 166: 303-310.

139. Dvorak AM, Kissell S. Granule changes of human skin mast cells characteristic of piecemeal degranulation and associated with recovery during wound healing in situ. J Leukoc Biol 1991; 49: 197-210.

140. Flaherty KR, Toews GB, Lynch JP 3rd, et al. Steroids in idiopathic pulmonary fibrosis: a prospective assessment of adverse reactions, response to therapy, and survival. Am J Med 2001; 110: 278-282.

141. Zisman DA, Lynch JP 3rd, Toews GB, Kazerooni EA, Flint A, Martinez FJ. Cyclophosphamide in the treatment of idiopathic pulmonary fibrosis: a prospective study in patients who failed to respond to corticosteroids. Chest 2000; 117: 1619-1626.

142. Raghu G, Depaso WJ, Cain K, et al. Azathioprine combined with prednisone in the treatment of idiopathic pulmonary fibrosis: a prospective double-blind, randomized, placebo-controlled clinical trial. Am Rev Respir Dis 1991; 144: 291-296.

143. Douglas WW, Ryu JH, Swensen SJ, et al. Colchicine versus prednisone in the treatment of idiopathic pulmonary fibrosis. A randomized prospective study. Members of the Lung Study Group. Am J Respir Crit Care Med 1998; 158: 220-225.

144. Raghu G, Johnson WC, Lockhart D, Mageto Y. Treatment of idiopathic pulmonary fibrosis with a new antifibrotic agent, pirfenidone: results of a prospective, open-label phase II study. Am J Respir Crit Care Med 1999; 159: 1061-1069. 
145. Ziesche R, Hofbauer E, Wittmann K, Petkov V, Block LH. A preliminary study of long-term treatment with interferon gamma$1 \mathrm{~b}$ and low-dose prednisolone in patients with idiopathic pulmonary fibrosis. N Engl J Med 1999; 341: 1264-1269.

146. Thannickal VJ, Lee DY, White ES, et al. Myofibroblast differentiation by transforming growth factor-beta 1 is dependent on cell adhesion and integrin signaling via focal adhesion kinase. $J$ Biol Chem 2003; 278: 12 384-12389.

147. Yoshida K, Kuwano K, Hagimoto N, et al. MAP kinase activation and apoptosis in lung tissues from patients with idiopathic pulmonary fibrosis. J Pathol 2002; 198: 388-396. 